\title{
Clinical Frailty Scale, K-FRAIL questionnaire, and clinical outcomes in an acute hospitalist unit in Korea
}

\author{
Seung Jun $\operatorname{Han}^{1,2}$, Hee-Won Jung, ${ }^{1,2,3}$, Jae Hyun Lee ${ }^{1,2}$, Jin Lim $^{1,2}$, Sung do Moon ${ }^{1,2}$, Sock-Won Yoon ${ }^{1,2}$, \\ Hongran Moon ${ }^{1,2}$, Seo-Young Lee ${ }^{1,2}$, Hyeanji Kim ${ }^{4}$, Sae-Rim Lee ${ }^{2}$, and Il-Young Jang ${ }^{3}$
}

\begin{abstract}
${ }^{1}$ Department of Internal Medicine, Seoul National University Hospital, Seoul; ${ }^{2}$ Hospital Medicine Center, Seoul National University Hospital, Seoul; ${ }^{3}$ Division of Geriatrics, Department of Internal Medicine, Asan Medical Center, University of Ulsan College of Medicine, Seoul; ${ }^{4}$ Regional Emergency Medical Center, Seoul National University Hospital, Seoul, Korea
\end{abstract}

Received: December 18, 2020 Revised : January 13, 2021 Accepted:January 18, 2021

\section{Correspondence to}

Hee-Won Jung, M.D.

Division of Geriatrics, Department of Internal Medicine, Asan Medical Center, University of Ulsan College of Medicine, 88 Olympic-ro 43-gil, Songpa-gu, Seoul 05505, Korea Tel: +82-2-3010-1852

Fax: +82-2-3010-1158

E-mail:dr.ecsta@gmail.com https://orcid.org/0000-00022583-3354
Background/Aims: Frailty increases the risks of in-hospital adverse events such as delirium, falls, and functional decline in older adults. We assessed the feasibility and clinical relevance of frailty status in Korean older inpatients using the Clinical Frailty Scale (CFS) and Korean version of the Fatigue, Resistance, Ambulation, Illnesses, \& Loss of Weight scale (K-FRAIL) questionnaires.

Methods: Frailty status was measured using the Korean-translated version of the CFS and K-FRAIL questionnaire within 3 days from admission in 144 consecutive patients aged 60 years or older. The correlation between CFS and K-FRAIL score was assessed. The criterion validity of CFS was assessed using receiver operating characteristic analysis. As outcomes, delirium, bedsore, length of stay (LOS), in-hospital mortality, and unplanned 30-day readmission were measured by reviewing medical records.

Results: The mean age of the study population was 70.1 years (range, 6o to 91), and 75 (52.1\%) were men. By linear regression analysis, CFS and K-FRAIL were positively correlated $(B=0.72, p<0.001)$. A CFS cutoff of $\geq 5$ maximized sensitivity + specificity to classify frailty using K-FRAIL as a reference (C-index $=0.893$ ). Higher frailty burden by both CFS and K-FRAIL was associated with higher LOS and bedsores. Unplanned readmission and in-hospital mortality were associated with higher CFS score but not with K-FRAIL score, after adjusting for age, gender, polypharmacy, and multimorbidity.

Conclusions: Frailty status by CFS was associated with LOS, bedsores, unplanned readmission, and in-hospital mortality. CFS can be used to screen high-risk patients who may benefit from geriatric interventions and discharge planning in acutely hospitalized older adults.

Keywords: Frailty; Prognosis; Hospitalists; Patient readmission

\section{INTRODUCTION}

Defined as a state of increased vulnerability to possible stressors with decreased physiological reserve associated with human aging, frailty is a common geriatric condition affecting up to $>20 \%$ of community-dwelling older adults in Korea [1,2]. Frailty increases the risks of developing adverse consequences including falls, functional decline, and mortality in community settings $[3,4]$. Frailty frequently accompanies multimorbidity and 
functional dependency and may deteriorate longitudinally in cycles of frailty [5]. However, frailty and associated geriatric conditions can be managed with appropriate intervention programs to prevent adverse outcomes such as functional decline even in resource-scarce public health settings $[6,7]$.

Compared to young adults, older adults tend to have a larger burden of chronic diseases in addition to subclinical organ pathology that accumulates with aging [8]. Many older patients experience hospitalization for acute or chronic conditions [9]. In Korea, $16.8 \%$ of older adults aged 65 years or older reported at least one hospitalization in the past year in 2017 [10]. In older hospitalized patients, frailty was associated with increased in-hospital or subsequent mortality, higher length of stay (LOS), functional decline, delirium, and institutionalization [11,12]. To prevent these adverse outcomes associated with acute inpatient care of frail older adults, acute geriatric medicine services have been developed, with improved clinical outcomes compared to those for usual care [13].

Screening frailty might be an initial clinical step to identify high-risk older patients to receive these patients centered services [14]. Among numerous frailty screening tools, the Clinical Frailty Scale (CFS) is a quick measure using function-focused descriptions and pictures that has been validated in a wide range of care settings including nursing homes, emergency departments (EDs), acute wards, and intensive care units $[15,16]$. With its outcome prediction abilities, the CFS was also proposed as a guide to rationing scarce medical resources in the coronavirus disease 2019 (COVID-19) pandemic. However, to our knowledge, no studies have yet evaluated the feasibility and possible roles of the CFS in hospitalized older patients in Korea. Thus, this study assessed the feasibility and clinical relevance of frailty status in Korean older inpatients using the Korean-translated version of the CFS, with the Korean version of the Fatigue, Resistance, Ambulation, Illnesses, \& Loss of Weight scale (K-FRAIL) questionnaire previously validated in Korean geriatric outpatients as a reference [17].

\section{METHODS}

\section{Study design and participants}

The internal medicine part of the hospital medicine center in Seoul National University Hospital, a tertiary teaching hospital, started frailty screening using the CFS and K-FRAIL in July 2020 as part of the process to identify candidate patients to receive inpatient medication reconciliation and patient-centered discharge planning services. A trained social worker measured the CFS, K-FRAIL within 72 hours of admission in patients aged 60 years older. We included patients admitted through both outpatient clinics and the ED. We excluded apparently terminal patients expected to die in fewer than 3 months due to cancer or uncontrolled underlying disease. For this study, we retrospectively reviewed the medical records of 144 patients admitted between July and November 2020, with available CFS and K-FRAIL scores.

\section{Frailty assessments}

We used the Korean-translated version of the CFS 2.0 (Supplementary Table 1), a screening measure with scores ranging from 1 (very fit) to 9 (terminally ill) that was previously validated with both frailty index and frailty phenotype in the Korean population and published elsewhere [18]. We considered CFS scores $\geq 5$ and $\leq 4$ to indicate frailty and non-frailty, respectively. We also used the K-FRAIL scale [17], a five-item questionnaire on fatigue, resistance, ambulation, illness, and loss of weight. We considered K-FRAIL scale scores with $\geq 3$ positive items to indicate frailty. These measures were assessed by interviewing patients or their proxy, focusing on their health state before (i.e., 2 weeks before) the current acute clinical issue that resulted in the index hospitalization, by a single social worker (S.R.L.) throughout the study. Recorded CFS and K-FRAIL were cross-checked by a physician (S.J.H.).

\section{Co-variables}

As clinical co-variables, we recorded the vital signs on the day of frailty assessments. For comorbidities, histories of clinical diagnoses of angina, arthritis, asthma, cancer, chronic lung disease, congestive heart failure, diabetes, myocardial infarction, hypertension, chronic kidney disease, and stroke were assessed by medical record review. Multimorbidity was defined as the presence of two or more chronic diseases. The numbers of different medications the patients were taking at admission were recorded, with polypharmacy defined as tak- 

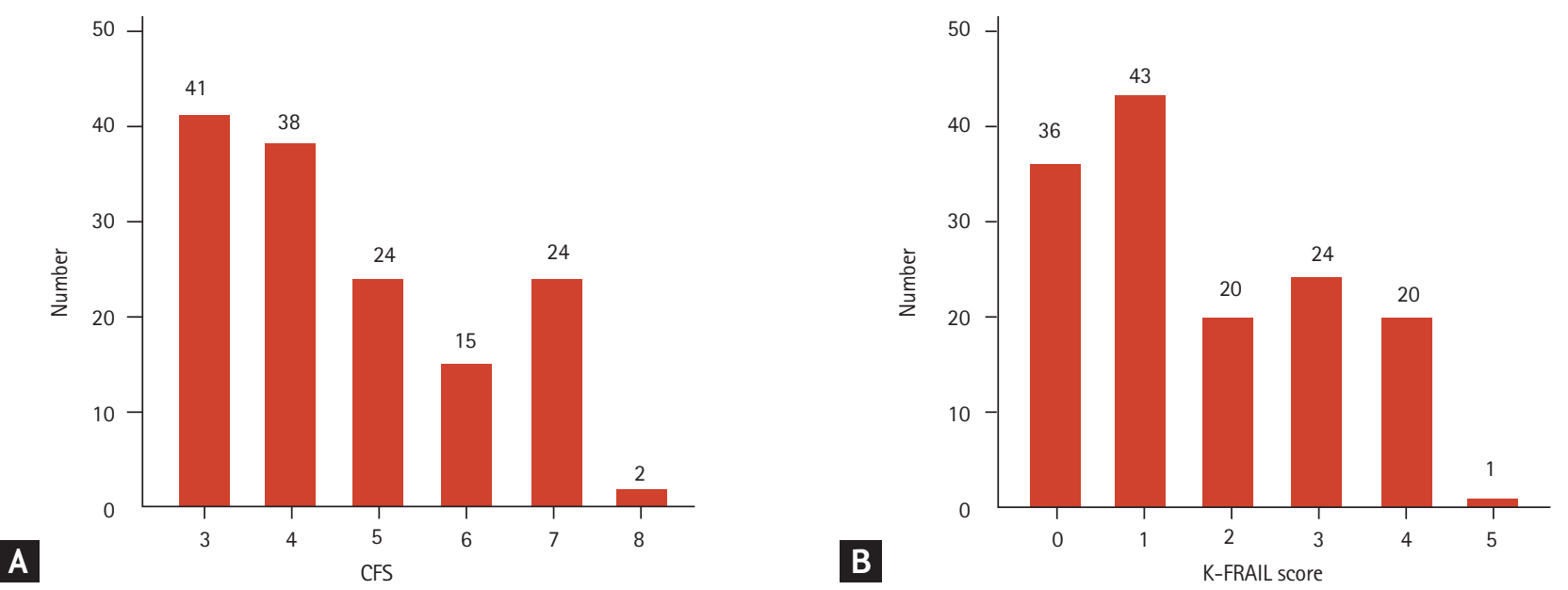

Figure 1. Distributions of (A) Clinical Frailty Scale (CFS) and (B) Korean version of the Fatigue, Resistance, Ambulation, Illnesses, \& Loss of Weight scale (K-FRAIL) scores in the study population.

ing five or more medications.

\section{Outcome measures}

As in-hospital complications, the incidence of clinically recorded delirium and bedsores either by physicians or nurses were reviewed. LOS was measured. Delirium, bedsore, in-hospital mortality, unplanned ED visits, and readmission within 30 days after discharge were assessed.

\section{Statistical analyses}

Continuous and categorical variables were expressed as mean \pm standard deviation $(\mathrm{SD})$ or numbers (\%). To compare parameters across frail- and non-frail groups by CFS, we used $t$ tests for continuous variables and chisquare tests for categorical variables. The correlations between age and CFS and K-FRAIL scale were evaluated by linear regression analysis to calculate the standardized beta (B) and were visualized using fractional polynomial regression analysis with 95\% confidence intervals. The correlation between the CFS and K-FRAIL scale was also assessed by linear regression analysis. Receiver operating characteristic (ROC) analysis was performed for CFS, with frailty by K-FRAIL questionnaire as the reference. The sensitivity and specificity for individual cutoffs and C-index were also calculated. The associations between baseline frailty status and the incidence of clinical outcomes were evaluated using univariate and multivariate logistic regression analyses, with adjustment for age, gender, and multimorbidity in the multivariate model. Two-sided $p$ values $<0.05$ were considered statistically significant. The statistical analyses were performed using Stata version 15.0 (StataCorp., College Station, TX, USA).

\section{Ethics statement}

The study protocol was reviewed and approved by the Institutional Review Board of Seoul National University Hospital (H-2012-059-1179), which waived the need for informed consent due to the retrospective nature of the study.

\section{RESULTS}

\section{Clinical characteristics}

In the study population, the mean age was 70.1 years (range, 60 to 91; SD, 7.2) and 52.1\% were men. The mean CFS score was 4.6 (range, 3 to 8; SD, 1.5) and 65 patients (45.1\%) had a CFS score of $\geq 5$. The mean K-FRAIL score was 1.7 (range, o to $5 ; \mathrm{SD}, 1.4$ ) and 45 patients $(31.3 \%$ ) were considered to be frail (K-FRAIL score $\geq 3$ ). The distributions of CFS and K-FRAIL scores are shown in Fig. 1. The clinical parameters of the study population are shown in Table 1. When the population was grouped into frail $(\mathrm{CFS} \geq 5)$ and non-frail $(\mathrm{CFS} \leq 4)$ groups, the patients with frailty were older, were frailer by K-FRAIL scale, had low diastolic blood pressure at admission, ex- 
Table 1. Clinical characteristics of the study population

\begin{tabular}{|c|c|c|c|}
\hline Variable & $\mathrm{CFS} \leq 4$ & $\mathrm{CFS} \geq 5$ & $p$ value \\
\hline Number & $79(54.9)$ & $65(45 \cdot 1)$ & \\
\hline Age, yr & $68.3 \pm 6.2$ & $72.2 \pm 7.9$ & 0.002 \\
\hline Men & $45(57 \cdot 0)$ & $30(46.2)$ & 0.196 \\
\hline Number of medications & $6.4 \pm 4.7$ & $7.1 \pm 4.8$ & 0.417 \\
\hline Polypharmacy & $43(66.4)$ & $43(54 \cdot 4)$ & 0.153 \\
\hline Multimorbidity & $34(43 \cdot 0)$ & $32(49.2)$ & $0.45^{8}$ \\
\hline Hypertension & $11(13.9)$ & $10(15 \cdot 4)$ & 0.805 \\
\hline Diabetes & $16(20.3)$ & $14(21.5)$ & 0.850 \\
\hline Cancer & $55(69.6)$ & $38(58.5)$ & 0.164 \\
\hline K-FRAIL score & $0.8 \pm 0.9$ & $2.7 \pm 1.2$ & $<0.001$ \\
\hline Frailty by K-FRAIL & $4(5.1)$ & $41(63.1)$ & $<0.001$ \\
\hline Height, cm & $158.8 \pm 15.1$ & $158.9 \pm 8.4$ & 0.963 \\
\hline $\mathrm{BMI}, \mathrm{kg} / \mathrm{m}^{2}$ & $23 \cdot 3 \pm 3.2$ & $22.7 \pm 3.6$ & 0.328 \\
\hline $\mathrm{SBP}, \mathrm{mmHg}$ & $124.6 \pm 17.6$ & $126.9 \pm 23.1$ & 0.512 \\
\hline $\mathrm{DBP}, \mathrm{mmHg}$ & $76.3 \pm 9.6$ & $72.9 \pm 10.2$ & 0.041 \\
\hline $\mathrm{HR}, / \mathrm{min}$ & $83.5 \pm 15.5$ & $86.3 \pm 17.2$ & 0.313 \\
\hline Length of stay, day & $6.8 \pm 8.4$ & $16.1 \pm 15 \cdot 7$ & $<0.001$ \\
\hline Delirium & $5(6.3)$ & $5(7 \cdot 7)$ & 0.749 \\
\hline Bedsore & $2(2.5)$ & $10(15 \cdot 4)$ & 0.007 \\
\hline Unplanned ED visit in 30 days & $10(12.7)$ & $13(20.6)$ & 0.200 \\
\hline Unplanned readmission in 30 days & $3(3.8)$ & $11(17 \cdot 5)$ & 0.009 \\
\hline In-hospital mortality & $1(1.3)$ & $3(4 \cdot 6)$ & 0.328 \\
\hline
\end{tabular}

Values are presented as number (\%) or mean \pm standard deviation.

CFS, Clinical Frailty Scale; K-FRAIL, Korean version of the Fatigue, Resistance, Ambulation, Illnesses, \& Loss of Weight scale; BMI, body mass index; SBP, systolic blood pressure; DBP, diastolic blood pressure; HR, heart rate; ED, emergency department.

perienced longer hospital stays, and were more likely to have bedsores and be re-admitted within 30 days after discharge.

\section{Content and criterion validity of CFS}

The CFS and K-FRAIL were both significantly correlated with age $\left(\mathrm{B}=0.35, R^{2}=0.121, p<0.001\right.$; and $\mathrm{B}=0.25, R^{2}=$ $0.061, p<0.001)$, respectively. The trends of the CFS and K-FRAIL scale and age are shown in Fig. 2. The CFS and K-FRAIL were correlated with each other $(B=0.72, p<$ $0.001, R^{2}=0.525$ ), as depicted in Fig. $3 \mathrm{~A}$.

The classification ability of the CFS was assessed using frailty by K-FRAIL scale as the reference. By ROC analysis (Fig. 3B), the C-index was 0.893 and a CFS cutoff of $\geq 5$ maximized sensitivity + specificity (Fig. $3 \mathrm{~B}$ and ${ }_{3} \mathrm{C}$ ).

\section{Frailty status and clinical outcomes}

The mean LOS was 10.4 days (SD, 12.2) in the study population. Higher frailty burden by both CFS $(B=0.47, p<$ 0.001 ) and K-FRAIL (B = 0.34, $p<0.001$ ) was associated with longer LOS in age- and gender-adjusted multivariate linear regression analysis.

During hospitalization, 10 patients (6.9\%) experienced delirium, 12 (8.3\%) had bedsores, and four (2.8\%) died. After discharge, $23(16.8 \%)$ patients experienced unplanned ED visits and 14 (10.2\%) experienced unplanned readmissions within 30 days. The presence of bedsores was associated with both CFS score and K-FRAIL, even after adjusting for age, gender, polypharmacy, and multimorbidity. In the univariate logistic analysis, unplanned readmission and ED visits were associated with higher CFS and K-FRAIL scores, respectively. When adjusted 

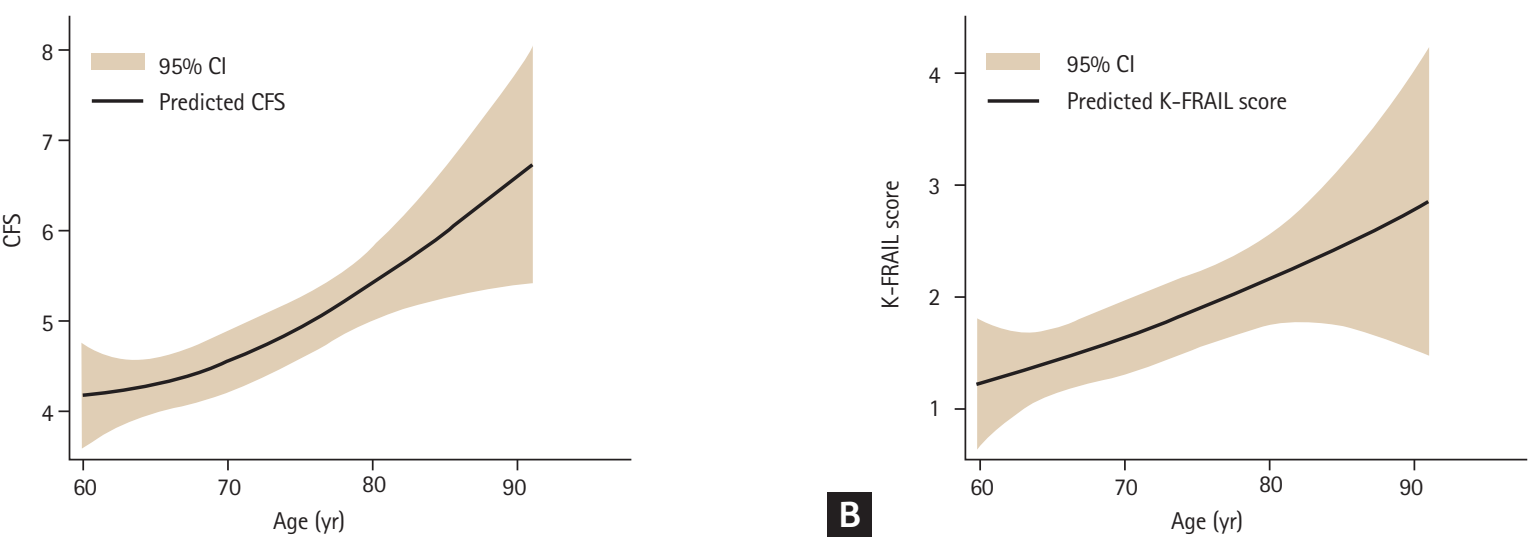

Figure 2. Trends of (A) Clinical Frailty Scale (CFS) and (B) Korean version of the Fatigue, Resistance, Ambulation, Illnesses, \& Loss of Weight scale (K-FRAIL) scores by age, as mean (line) and 95\% confidence interval (CI; shaded area) calculated by fractional polynomial regression analysis.

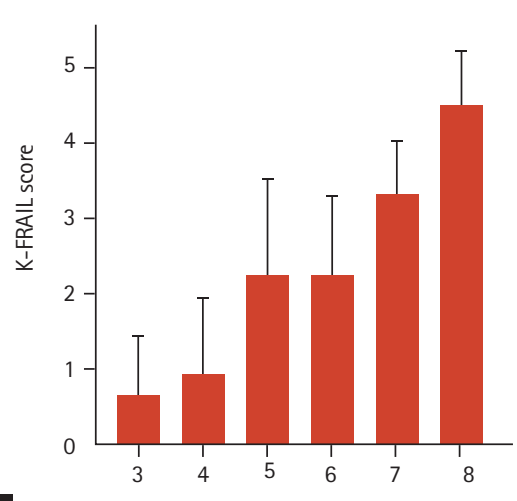

A

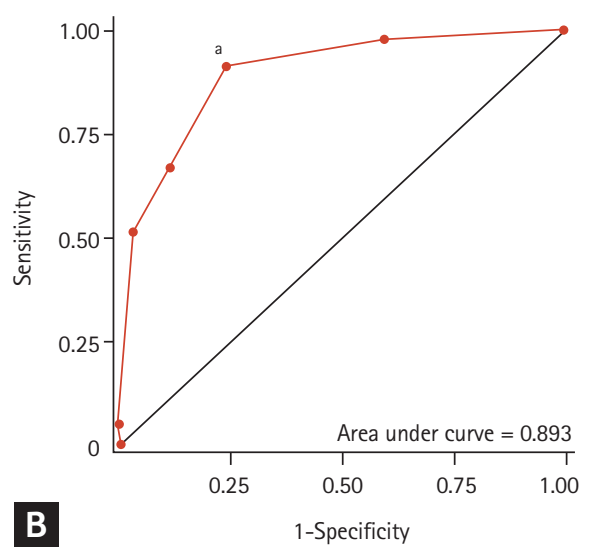

\begin{tabular}{ccc}
\hline Cotoff & Sen & Spe \\
\hline$\geq 3$ & $100.00 \%$ & $0.00 \%$ \\
$\geq 4$ & $97.80 \%$ & $40.40 \%$ \\
$\geq 5$ & $91.10 \%$ & $75.80 \%$ \\
$\geq 6$ & $63.70 \%$ & $88.90 \%$ \\
$\geq 7$ & $51.10 \%$ & $97.00 \%$ \\
$\geq 8$ & $4.40 \%$ & $100.00 \%$ \\
\hline
\end{tabular}

C

Figure 3. Means (bars) and standard deviations (whiskers) of the Korean version of the Fatigue, Resistance, Ambulation, Illnesses, \& Loss of Weight scale (K-FRAIL) scores by corresponding Clinical Frailty Scale (CFS) scores (A), receiver operating characteristics (B) curve of CFS score with frailty by K-FRAIL $(\geq 3)$ as the reference, and a sensitivity (Sen)/specificity (Spe) table for specific CFS scores to classify frailty by K-FRAIL (C). ${ }^{\mathrm{a}} \mathrm{CFS}$ of 5 or higher maximized Sen + Spe in determining frailty by K-FRAIL.

for age, gender, polypharmacy, and multimorbidity, the CFS remained significantly associated with unplanned readmission, while the association between K-FRAIL and ED visit became attenuated. In-hospital mortality was marginally associated with higher K-FRAIL scores in univariate logistic analysis, although this association was not significant after adjustment. In contrast, the CFS remained significant in predicting in-hospital mortality after adjustment, although this association was not significant in unadjusted analysis (Table 2).

\section{DISCUSSION}

In this study, we found that the CFS correlated with the K-FRAIL and could classify frailty status by K-FRAIL score, a tool previously validated in the Korean population in hospitalized older patients. A higher CFS score was associated with a longer hospital stay, bedsores, unplanned readmission, and in-hospital mortality even after adjusting for age, gender, polypharmacy, and multimorbidity. To our knowledge, this is the first study to report the clinical relevance of the CFS in hospitalized patients in Korea. 
Table 2. Clinical outcomes and frailty status by CFS and K-FRAIL questionnaires at admission

\begin{tabular}{|c|c|c|c|c|}
\hline \multirow{2}{*}{ Variable } & \multicolumn{2}{|c|}{ Model 1} & \multicolumn{2}{|c|}{ Model 2} \\
\hline & OR & $95 \% \mathrm{CI}$ & OR & $95 \% \mathrm{CI}$ \\
\hline \multicolumn{5}{|l|}{ Delirium } \\
\hline CFS & 1.36 & $0.89-2.07$ & 1.24 & $0.78-1.98$ \\
\hline K-FRAIL & 1.47 & $0.93-2.31$ & 1.41 & $0.89-2.23$ \\
\hline \multicolumn{5}{|l|}{ Bedsore } \\
\hline CFS & 1.63 & $1.09-2.45$ & 1.66 & $1.07-2.58$ \\
\hline K-FRAIL & 1.56 & $1.02-2.39$ & 1.59 & $1.01-2.50$ \\
\hline \multicolumn{5}{|c|}{ Unplanned readmission in 30 days } \\
\hline CFS & 1.50 & $1.03-2.18$ & 1.54 & $1.01-2.36$ \\
\hline K-FRAIL & 1.47 & $0.99-2.17$ & 1.46 & $0.96-2.20$ \\
\hline \multicolumn{5}{|c|}{ Unplanned ED visit in 30 days } \\
\hline CFS & 1.32 & $0.98-1.78$ & 1.19 & $0.85-1.65$ \\
\hline K-FRAIL & 1.43 & $1.04-1.97$ & 1.35 & $0.97-1.88$ \\
\hline \multicolumn{5}{|c|}{ In-hospital mortality } \\
\hline CFS & 2.15 & $0.98-4.70$ & 2.56 & $1.02-6.43$ \\
\hline K-FRAIL & 2.41 & $1.00-5.81$ & 2.59 & $1.00-6.73$ \\
\hline
\end{tabular}

Model 1, unadjusted; Model 2, adjusted for age, gender, polypharmacy, and multimorbidity.

CFS, Clinical Frailty Scale; K-FRAIL, Korean version of the Fatigue, Resistance, Ambulation, Illnesses, \& Loss of Weight scale; OR, odds ratio; CI, confidence interval; ED, emergency department.

Our observations of the clinical outcomes with the CFS are consistent with those of previous studies performed in acute inpatients $[12,16]$. In the present study, the CFS predicted LOS and unplanned readmission after adjusting for age and gender, concordant with previous observations from other countries [19,20]. Although the associations of CFS and unplanned ED visits were attenuated after adjusting for age and gender, the general trends suggested a significant association of the CFS with outcomes in a larger population, as shown in a study in Canada [21]. While the CFS was associated with the detection of bedsores during hospitalization, outcomes such as deconditioning or subsequent institutionalization were not available in our study, although existing literature supports the use of the CFS to predict high-risk patients with functional decline [22].

The clinical importance of frailty as a risk-stratifying measure has been studied in patients with varying clinical conditions or in acute to chronic care settings, as well as community-dwelling older population [4]. The outcome prediction abilities of frailty in specialties entailing cardiology and cardiac surgery [23], general sur- gery [11], nephrology [24], oncology [25], hepatology [26], emergency medicine [27], and critical care [28] have been extensively reported, with specialties other than geriatrics now embracing frailty as an important parameter that deserves geriatric attention to improve clinical outcomes.

In Korean acute hospitals, however, assessments of frailty in inpatients are rarely performed except for a few hospitals with geriatric medicine services [29]. While measures focusing on older patients such as fall prevention, discharge planning, and social welfare services are available in some hospitals, case-finding and coordination are mostly performed ad hoc, without evaluation of frailty or other geriatric problems [29]. Consequently, many older, vulnerable patients are currently left with unmet needs in the medical and functional domains. Therefore, frailty screening measures that have been validated in acute hospital settings may help identify high-risk patients who may benefit from inpatient-focused services $[14,30,31]$.

The results of the present study demonstrated that the CFS can be used as a quick screening measure of high- 
risk older patients in hospitalist units. Since hospital medicine provides global medical care and functional demands of hospitalized patients, adopting the concept of frailty may facilitate the coordination of various patient-centered programs including risk prevention measures for adverse outcomes such as falls, delirium, and bedsores [32]; translation care planning services involving pharmacists and social workers [33]; and care planning entailing advance directives and deprescribing [34]. With hospital medicine in Korea rapidly expanding to address the soaring demand for in-hospital care with population aging, adopting frailty-based care coordination may also alleviate the ever-increasing and unmet geriatric care needs [29].

Our study has several limitations. The study was performed in a single tertiary center, in which a high proportion of patients have cancers as key clinical problems [35,36], limiting the generalizability of our results to other acute or chronic care settings across Korea. Also, data on outcomes such as longer-term mortality and functional deterioration were not available in the current study design. Larger, longitudinally designed studies in hospitalized older patients with detailed functional measurements are warranted. We used the K-FRAIL, another screening tool, as a reference measure of frailty in this study, rather than the frailty index, since comprehensive geriatric assessment (CGA) was not available in the study setting. Consequently, a detailed analysis of the content and construct validities of CFS was not possible in our study. However, an ongoing study comparing the Korean version of the CFS to geriatric parameters using the CGA in another population may overcome this weakness of the present study. In this study, due to the retrospective nature, we had to rely on information on sore and delirium using medical records documented by physicians and nurses. Therefore, whether recorded sores were newly developed or already existed are not clearly assessible in the present analysis, thus limiting its value as outcomes. Also, without structured delirium screening or surveillance measures, deliriums could be under detected in the current retrospective study. Surveillance on geriatric outcomes such as delirium and sore using validated instruments in the future prospective study might be helpful to alleviate possible limitations of this study.

In conclusion, frailty status according to CFS score was associated with LOS, bedsores, unplanned readmission, and in-hospital mortality among inpatients of a hospitalist unit in a tertiary hospital. The CFS can be used to screen high-risk patients who may benefit from geriatric interventions and discharge planning in acutely hospitalized older adults.

\section{KEY MESSAGE}

1. The Korean-translated Clinical Frailty Scale (CFS) determined frailty status according to Korean version of the Fatigue, Resistance, Ambulation, Illnesses, \& Loss of Weight scale (K-FRAIL) score in hospitalized older patients.

2. Worse baseline CFS was associated with longer length of stay, increased risk of in-hospital mortality, and unplanned 30-day readmission after discharge.

3. The CFS may be used to screen high-risk older patients in acute-care hospitals.

\section{Conflict of interest}

No potential conflict of interest relevant to this article was reported.

\section{Acknowledgments}

This study was supported by grant No.0420202070 from the Seoul National University Hospital Research Fund and a grant from the Korea Health Technology R\&D project through the Korea Health Industry Development Institute (KHIDI) funded by the Ministry of Health \& Welfare, Republic of Korea (grant no. HI18C2383).

\section{REFERENCES}

1. Jung HW, Jang IY, Lee YS, et al. Prevalence of frailty and aging-related health conditions in older Koreans in rural communities: a cross-sectional analysis of the aging study of Pyeongchang rural area. J Korean Med Sci 2016;31:345-352.

2. Jung HW, Kim SW, Ahn S, et al. Prevalence and outcomes of frailty in Korean elderly population: comparisons of a multidimensional frailty index with two phenotype models. PLoS One 2014;9:e87958. 
3. Jang IY, Lee E, Lee H, et al. Characteristics of sarcopenia by European consensuses and a phenotype score. J Cachexia Sarcopenia Muscle 2020;11:497-504.

4. Hoogendijk EO, Afilalo J, Ensrud KE, Kowal P, Onder G, Fried LP. Frailty: implications for clinical practice and public health. Lancet 2019;394:1365-1375.

5. Fried LP, Tangen CM, Walston J, et al. Frailty in older adults: evidence for a phenotype. J Gerontol A Biol Sci Med Sci 2001;56:M146-M156.

6. Park CM, Oh G, Lee H, et al. Multicomponent intervention and long-term disability in older adults: a nonrandomized prospective study. J Am Geriatr Soc 2021;69:669677 .

7. Jang IY, Jung HW, Park H, et al. A multicomponent frailty intervention for socioeconomically vulnerable older adults: a designed-delay study. Clin Interv Aging 2018;13:1799-1814.

8. Jung HW, Kim KI. Multimorbidity in older adults. J Korean Geriatr Soc 2014;18:65-71.

9. Collins JL. Aging in good health. Chronic Dis Notes Rep 2007;18:3-6.

10. Jang IY, Lee HY, Lee E; 5oth Anniversary Committee of Korean Geriatrics Society. Geriatrics fact sheet in Korea 2018 from national statistics. Ann Geriatr Med Res 2019;23:50-53.

11. Kim SW, Han HS, Jung HW, et al. Multidimensional frailty score for the prediction of postoperative mortality risk. JAMA Surg 2014;149:633-640.

12. Cunha AIL, Veronese N, de Melo Borges S, Ricci NA. Frailty as a predictor of adverse outcomes in hospitalized older adults: a systematic review and meta-analysis. Ageing Res Rev 2019;56:100960.

13. Fox MT, Persaud M, Maimets I, et al. Effectiveness of acute geriatric unit care using acute care for elders components: a systematic review and meta-analysis. J Am Geriatr Soc 2012;60:2237-2245.

14. Lee H, Lee E, Jang IY. Frailty and comprehensive geriatric assessment. J Korean Med Sci 2020;35:e16.

15. Rockwood K, Theou O. Using the clinical frailty scale in allocating scarce health care resources. Can Geriatr J 2020;23:210-215.

16. Church S, Rogers E, Rockwood K, Theou O. A scoping review of the Clinical Frailty Scale. BMC Geriatr 2020;20:393.

17. Jung HW, Yoo HJ, Park SY, et al. The Korean version of the FRAIL scale: clinical feasibility and validity of assessing the frailty status of Korean elderly. Korean J Intern
Med 2016;31:594-600.

18. Jung HW, Jang IY, Back JY, et al. Validity of the clinical frailty scale in Korean older patients at a geriatric clinic. Korean J Intern Med 2021;36:1242-1250.

19. Chong E, Ho E, Baldevarona-Llego J, et al. Frailty in hospitalized older adults: comparing different frailty measures in predicting short- and long-term patient outcomes. J Am Med Dir Assoc 2018;19:450-457.

20. Juma S, Taabazuing MM, Montero-Odasso M. Clinical Frailty Scale in an acute medicine unit: a simple tool that predicts length of stay. Can Geriatr J 2016;19:34-39.

21. Kahlon S, Pederson J, Majumdar SR, et al. Association between frailty and 30-day outcomes after discharge from hospital. CMAJ 2015;187:799-804.

22. Basic D, Shanley C. Frailty in an older inpatient population: using the clinical frailty scale to predict patient outcomes. J Aging Health 2015;27:670-685.

23. Kim DH, Afilalo J, Shi SM, et al. Evaluation of changes in functional status in the year after aortic valve replacement. JAMA Intern Med 2019;179:383-391.

24. Schopmeyer L, El Moumni M, Nieuwenhuijs-Moeke GJ, Berger SP, Bakker SJL, Pol RA. Frailty has a significant influence on postoperative complications after kidney transplantation: a prospective study on short-term outcomes. Transpl Int 2019;32:66-74.

25. Hamaker ME, Jonker JM, de Rooij SE, Vos AG, Smorenburg CH, van Munster BC. Frailty screening methods for predicting outcome of a comprehensive geriatric assessment in elderly patients with cancer: a systematic review. Lancet Oncol 2012;13:e437-e444.

26. Laube R, Wang H, Park L, et al. Frailty in advanced liver disease. Liver Int 2018;38:2117-2128.

27. Brousseau AA, Dent E, Hubbard R, et al. Identification of older adults with frailty in the Emergency Department using a frailty index: results from a multinational study. Age Ageing 2018;47:242-248.

28. Muscedere J, Waters B, Varambally A, et al. The impact of frailty on intensive care unit outcomes: a systematic review and meta-analysis. Intensive Care Med 2017;43:11051122.

29. Jung HW, Lim JY. Geriatric medicine, an underrecognized solution of precision medicine for older adults in Korea. Ann Geriatr Med Res 2018;22:157-158.

30. Jung HW. Visualizing domains of comprehensive geriatric assessments to grasp frailty spectrum in older adults with a radar chart. Ann Geriatr Med Res 2020;24:55-56. 
31. McGrath J, Almeida P, Law R. The Whittington Frailty Pathway: improving access to comprehensive geriatric assessment: an interdisciplinary quality improvement project. BMJ Open Qual 2019;8:eooo798.

32. Choi JY, Kim KI, Kang MG, et al. Impact of a delirium prevention project among older hospitalized patients who underwent orthopedic surgery: a retrospective cohort study. BMC Geriatr 2019;19:289.

33. Moro Agud M, Menendez Colino R, Mauleon Ladrero Mdel C, et al. Analysis of an electronic medication reconciliation and information at discharge programme for frail elderly patients. Int J Clin Pharm 2016;38:996-1001.
34. Curtin D, Gallagher P, O'Mahony D. Deprescribing in older people approaching end-of-life: development and validation of STOPPFrail version 2. Age Ageing 2021;50:465-471.

35. Lee JH, Jung HW, Jang IY, do Moon S, Lee S, Han SJ. Anticholinergic cognitive burden as a predictive factor for in-hospital mortality in older patients in Korea. Ann Geriatr Med Res 2020;24:20-26.

36. Han SJ, Jung HW, Oh DY, et al. Comparisons of clinical outcomes between weekday-only and full-time, 24-hour/7-day coverage hospitalist systems. J Korean Med Sci 2020;35:e117. 
Supplementary Table 1. Clinical Frailty Scale

\begin{tabular}{|c|c|c|c|}
\hline$\square$ & 1 & $\begin{array}{l}\text { 매우 건강 } \\
\text { (Very Fit) }\end{array}$ & $\begin{array}{l}\text { 강건하고, 활동적이며, 활력이 넘치고, 의욕이 넘치는 사람. 보통 규칙적으로 운동 } \\
\text { 하며, 동년배에서 가장 건강한 편. }\end{array}$ \\
\hline$\square$ & 2 & 건강(Well) & $\begin{array}{l}\text { 현재 활동적인 질병, 증상은 없지만 매우 건강한 상태는 아님. 가끔(특정 계절 } \\
\text { 한정 등) 격렬한 활동 혹은 운동을 함. }\end{array}$ \\
\hline$\square$ & 3 & $\begin{array}{l}\text { 건강관리 우수 } \\
\text { (Managing Well) }\end{array}$ & $\begin{array}{l}\text { 의학적 문제를 비교적 잘 관리하고 있으나 일상적인 활동(걷기 등) 이상의 다른 } \\
\text { 격렬한 활동을 하지 않는 사람. }\end{array}$ \\
\hline$\square$ & 4 & $\begin{array}{l}\text { 아주 경미한 허약 } \\
\text { (Living with very } \\
\text { mild frailty) }\end{array}$ & $\begin{array}{l}\text { 일상생활에 타인에게 도움을 받을 정도는 아니나, 본인의 상태로 인해 활동이 } \\
\text { 제한되는 경우가 많음. 활동이 느려지거나, 일과중에 피곤함을 느끼는 증상이 } \\
\text { 대표적. 생활에 타인의 도움이 서서히 필요해지는 상태. }\end{array}$ \\
\hline$\square$ & 5 & $\begin{array}{l}\text { 경미한 허약 } \\
\text { (Mildly Frail) }\end{array}$ & $\begin{array}{l}\text { 행동 둔화의 양상을 보이며, 다소 어려운 도구적 일상생활 수행에는 도움이 필요 } \\
\text { 함. 대부분의 경미한 허약을 가진 사람들은 점차 쇼핑, 야외에서 혼자 걷는 것, } \\
\text { 식사 준비, 집안일등을 수행하기 어려워지게 됨. }\end{array}$ \\
\hline$\square$ & 6 & $\begin{array}{l}\text { 중등도 허약 } \\
\text { (Moderately Frail) }\end{array}$ & $\begin{array}{l}\text { 모든 외부활동과 집안일에 도움이 필요함. 실내에서는 계단 오르기, 목욕 등을 } \\
\text { 혼자 할 수 없는 경우가 많고 옷 입기에도 약간의 보조가 필요할 수 있음. }\end{array}$ \\
\hline$\square$ & 7 & $\begin{array}{l}\text { 중증 허약 } \\
\text { (Severely Frail) }\end{array}$ & $\begin{array}{l}\text { 신체적 혹은 인지적인 이유로 타인에게 완전히 의존하고 있으나 상태가 안정적이 } \\
\text { 고 사망 위험(6개월 이내)도 높지 않아 보임. }\end{array}$ \\
\hline$\square$ & 8 & $\begin{array}{l}\text { 초고도 허약 } \\
\text { (Very Severely Frail) }\end{array}$ & $\begin{array}{l}\text { 수명이 얼마 남지 않은 상태로 일상생활을 타인에게 전적으로 의존함. 사소한 } \\
\text { 질병에서도 회복하기 어려움. }\end{array}$ \\
\hline$\square$ & 9 & $\begin{array}{l}\text { 불치병 환자 } \\
\text { (Terminally III) }\end{array}$ & $\begin{array}{l}\text { 임종이 얼마 남지 않은 상태. 암 등 두드러지는 기저질환에 의해 6개월 이하의 } \\
\text { 기대수명 상태. }\end{array}$ \\
\hline
\end{tabular}

Adapted from Rockwood et al. [15]. 